\title{
Phenolic Constituents, Antimicrobial and Antioxidant Properties of Blueberry Leaves (V5)
}

\author{
Song Xiaoyong ${ }^{1, *}$, Cheng Luming ${ }^{2}$ \\ ${ }^{1}$ North China University of Water Resources and Electric Power, Zhengzhou, China \\ ${ }^{2}$ The Second Hospital Affiliated to Zhengzhou University, Zhengzhou, China \\ *Corresponding author: songxiaoyong@ncwu.edu.cn
}

Received November 03, 2014; Revised November 17, 2014; Accepted November 21, 2014

\begin{abstract}
This study assessed polyphenol compositions, antioxidant and antimicrobial characteristics of blueberry-leaf extracts. Four different solvents (70\% acetone, 100\% methanol,50\% and 95\% ethanol) were applied. Results showed phenolic compounds were identified as quercetin, kaempferol, gallic, protocatechui, caffeic, vanillic, syringic, p-coumaric andferulic acids. Caffeic acid was the foremost component in 50\% ethanol, $70 \%$ acetone and methanol extracts, whereas protocatechui acid was the major compound in $95 \%$ ethanol extracts. The methanol extracts showed the highest total phenols, tannin and DPPH scavenging activity, and the $50 \%$ ethanol extracts had the greatest reducing power and ORAC values. The lowest contents of total phenols and tannin were in 95\% ethanol and $70 \%$ acetone extracts, respectively. All extracts demonstrated the antimicrobial activity against $E$. coli, L.monocytogenes, S.typhimurium, S. aureus and fungi, except for the 95\% ethanol extract against L.monocytogenes. The $50 \%$ ethanol extracts showed the highest inhibitory effect against $S$. aureus with the lowest minimum inhibitory concentration (MIC) against all tested microbes. The greatest inhibition zone and the smallest MIC against fungi were found in the $95 \%$ ethanol and methanol extracts. These results indicated that the blueberry leaves are good source of polyphenols and could be used as natural antioxidant and antimicrobial agent.
\end{abstract}

Keywords: blueberry leaf, extraction solvent, polyphenols, antioxidant property, antimicrobial activity

Cite This Article: Song Xiaoyong, and Cheng Luming, "Phenolic Constituents, Antimicrobial and Antioxidant Properties of Blueberry Leaves (V5).” Journal of Food and Nutrition Research, vol. 2, no. 12 (2014): 973-979. doi: 10.12691/jfnr-2-12-18.

\section{Introduction}

There are increased interest in the use of plant extracts as natural antimicrobial and antioxidant agents, especially in food, cosmetic, medical and agrochemical areas [1,2,3]. Phenolic compounds including tannins, terpenoids, alkaloids and flavonoidsin plant extracts have or show good antioxidant and antimicrobial abilities [1,4]. Blueberry has been heralded as a "superfood" due to rich nutrients and bioactive substances. As a result, the worldwide production of blueberry has increased from just over 50,000 acres to nearly 190,000 acres in the past fifteen years.

The blooming blueberry industry has produced large amount of blueberry-leaf wastes. Therefore, it is necessary to convert this waste into higher added-value products. Several studies have shown that blueberry leaves are important sources of polyphenols including phenolic acids and flavonoids and possessed potential antioxidant capacity [5]. Moreover, both yield and biological activity of the plant extracts are highly related to the extraction solvents employed $[6,7,8]$. It has been reported the characteristics of the extraction solvents noticeably affect the total phenolic content $( \pm 25 \%$ variation $)$ and antioxidant activity (up to $30 \%$ variation) of the plant extracts [9]. The ethanolic extracts of rabbiteye blueberry leaves contained higher total phenolic content and total flavonoid content, and had higher antioxidant activity than that in blueberry fruits [10]. And the water extracts of blueberry leaf infusions had significant reduced capacity and radical scavenging potential [11].

However, little is known about the antimicrobial potential of the blueberry leaf extracts $[1,4,11]$. Therefore, it is necessary to investigate the extraction efficiency, antioxidant and antimicrobial activities of blueberry leaf extracts using different solvents for developing more effective and economic application of this natural antibacterial and antioxidant agent.

The objectives of this study were: 1) to firstly evaluate the antimicrobial properties of blueberry leaf extracts,2) to investigate the influences of the extract solvents (ethanol, acetone and methanol) on the phenolic components, the total phenolic contents and tannins concentrations in the extracts, and 3) to determine the correlations between the contents of bioactive agents and different antioxidant abilities.

\section{Materials and Methods}

\subsection{Materials}


Blueberry (genus vaccinium V5) leaves were collected from Qingpu Modern Agricultural Park (Shanghai, China) in 2014 at commercial mature stage of the blueberry fruit and separated by hands to get rid of debris. The leaves were immediately freeze-dried (Freezone 2.5L Triad, Labconco Inc., USA) and stored at $-80^{\circ} \mathrm{C}$ until usage. All standards were obtained from Sigma Aldrich (St. Louis, USA) and all chemical agents were purchased from Sinopharm Chemical Reagent Co., Ltd (Shanghai, China). Nutrient broth and plate count agar were obtained from Beijing Land Bridge Technology Co., Ltd (Beijing, China). Potato dextrose agar medium was from Hangzhou Tianhe Microorganism Reagent Co., Ltd. (Hangzhou, China).

\subsection{Phenolic Extraction}

Previous studies showed that the $50 \%$ ethanol extracts from the plant tissues have higher total phenolic content and antioxidant activity than the ethanol, methanol or $50 \%$ methanol aqueous extracts [6].The $70 \%$ (v/v) aqueous acetone and $95 \%(\mathrm{v} / \mathrm{v})$ ethanol were commonly used for extraction of tannins and other classes of phenolic compounds from plant materials [12]. And pure methanol was the best solvent for extracting phenolic compounds in plant tissues, followed by ethanol, diethylether and hexane [13]. Therefore, the 50\% ethanol (v/v), 95\% ethanol (v/v), $70 \%$ acetone $(\mathrm{v} / \mathrm{v})$ and $100 \%$ methanol were used for extracting phenolic compounds from the blueberry leaves, respectively. For ethanol extraction, leaf powders were transferred to dark-colored flasks, and homogenized with $50 \%$ or $95 \%$ ethanol at a material to solvent ratio of $15: 100(\mathrm{~m} / \mathrm{v})$ at $25^{\circ} \mathrm{C}$ for $30 \mathrm{~min}$. For acetone and methanol extractions, the powder samples were mixed with $70 \%$ acetone or pure methanol at $25^{\circ} \mathrm{C}$ for $30 \mathrm{~min}$ with a material to solvent ratio of 1:10 (w/v). After twice extractions with each selected solvent, two extracts were collected and pooled into a round-bottomflask, and then evaporated to near dry under vacuum at $40^{\circ} \mathrm{C}$ using a rotary evaporator (Models RE-52AA, Yuhua Instruments Co., Henan, China). The residual was re-dissolved in $1 \%$ $(\mathrm{v} / \mathrm{v})$ the corresponding solvent to $50 \mathrm{~mL}$, and then stored at $-80^{\circ} \mathrm{C}$ until further analysis.

\subsection{Total Phenolics Content (TPC) Assay}

TPC was determined using the Folin-Ciocalteureagent, following the method described by Moulehi et al. [13] with some modifications. Briefly, the extract was then diluted with water to $50 \mathrm{~mL}$. A $7.5 \mathrm{~mL}$ of deionized water and a $0.5 \mathrm{~mL}$ of Folin-Ciocalteau reagent were added into $0.5 \mathrm{~mL}$ of diluted sample extract or $0.5 \mathrm{~mL}$ gallic acid solutions $\left(0,50,100,150\right.$, or $\left.200 \mathrm{mg} \mathrm{kg}^{-1}\right)$ in a series of test tubes, respectively. After sitting at room temperature for $10 \mathrm{~min}$, the solutions were mixed with $3 \mathrm{~mL}$ of $20 \%$ $(\mathrm{m} / \mathrm{v}) \mathrm{Na}_{2} \mathrm{CO}_{3}$, placed in a water bath at $40^{\circ} \mathrm{C}$ for $20 \mathrm{~min}$, and then immediately cooled to room temperature in an ice bath for $3 \mathrm{~min}$. The absorbance of the samples and standards were measured spectrophotometrically (UV1800, Kyoto, Japan) at $765 \mathrm{~nm}$. Triplicate extractions were performed for each sample. TPC was calculated as $\mathrm{mg}$ of gallic acid equivalents (GAE)/g dry mass (DM) sample.

\subsection{Phenolics Profile Identified by HPLC}

The phenolics profile of the different solvent extracts was analyzed on an Agilent 2489 infinity HPLC using a Zorbax Eclipse XDB-C18 column $(250 \mathrm{~mm} \times 4.6 \mathrm{~mm}$, $5 \mu \mathrm{m}$, Waters, CA, USA), following the method described by Roby et al. [3] with some modifications. The phenolic compounds were separated using a gradient elution program with a mobile phase containing solvent A (acetic acid $/ \mathrm{H}_{2} \mathrm{O}, 2: 98, \mathrm{v} / \mathrm{v}$ ) and solvent $\mathrm{B}$ (acetic acid/acetonitrile/ $\mathrm{H}_{2} \mathrm{O}, 2: 30: 68$, v/v/v). Separation was achieved through a gradient elution as follows: solvent $\mathrm{B}$ from $10 \%$ - 100\% within $42 \mathrm{~min}$ and allow $33 \mathrm{~min}$ of post-run for reconditioning. An injection volume of $20 \mu \mathrm{L}$ with $1 \mathrm{~mL} / \mathrm{min}$ flow rate was used. Identification of the phenolic compounds was accomplished by comparing the retention time and spectrum of the peaks in the samples to that of the standards under the same HPLC conditions. Quantification of each phenolic acid was determined using external standards and total area under $280 \mathrm{~nm}$ wavelength.

\subsection{Tannin Content Assay}

Tannins were determined according to Chinese national standard NY/T 1600-2008 [14]. Briefly, the reaction mixture contained $1 \mathrm{~mL}$ tannin extract solution, $2.5 \mathrm{~mL}$ Folin-Danis reagent (containing $100 \mathrm{gNa}_{2} \mathrm{WO}_{4} \cdot 2 \mathrm{H}_{2} \mathrm{O}, 20 \mathrm{~g}$ $\mathrm{H}_{3} \mathrm{Mo}_{12} \mathrm{O}_{40} \mathrm{P} . \mathrm{XH}_{2} \mathrm{O}$, 50ml phosphomolybdic acid solution in a total volume of $1000 \mathrm{ml}), 5 \mathrm{~mL} 7.5 \%$ (w/v) $\mathrm{Na}_{2} \mathrm{CO}_{3}$ solution and deionized water in a total reaction volume of $50 \mathrm{~mL}$. The reaction mixture was incubated at room temperature for $30 \mathrm{~min}$. The absorbance was read immediately at $760 \mathrm{~nm}$ using a spectrophotometer (Shimadzu Co., Ltd., ModelUV-1800, Japan).

\subsection{Antioxidant Activity}

\subsubsection{DPPH Scavenging Activity}

The DPPH (2,2-diphenyl-1-picryhydrazyl) assay was used to measure radical scavenging activity [15] and radical scavenging activity of the samples was reported as mg of ascorbic acid equivalents (AAE)/g DM sample. In brief, diluted sample extract or $0-0.04 \mathrm{mg} / \mathrm{mL}$ of ascorbic acid solution $(1.5 \mathrm{ml})$ were mixed with $3 \mathrm{~mL}$ of 0.09 $\mathrm{mg} / \mathrm{mL}$ DPPH solution and placed at room temperature for $5 \mathrm{~min}$ in dark. Then the absorbance was determined by a spectrophotometer at $517 \mathrm{~nm}$. The assay was done in triplicate.

\subsubsection{Reducing Power (RF) Assay}

The RF was determined according to the procedure of Kaneria and Chanda [7], and ascorbic acid was used as positive control. A $1 \mathrm{~mL}$ sample extracts were mixed with $2.5 \mathrm{~mL}$ of sodium phosphate buffer (50 mM, pH 7.0) and $2.5 \mathrm{~mL}$ of $1 \%$ potassium ferricyanide incubated at $50^{\circ} \mathrm{C}$ for $20 \mathrm{~min}$, and then a $2.5 \mathrm{~mL}$ of $10 \%$ trichloroacetic acid $(\mathrm{w} / \mathrm{v})$ was added. The mixture was centrifuged at 3000 rpm for $10 \mathrm{~min}$. The supernatant $(2.5 \mathrm{~mL})$ was mixed with $2.5 \mathrm{~mL}$ of deionized water and $0.5 \mathrm{~mL}$ of $0.1 \%$ ferric chloride. The absorbance was measured at $700 \mathrm{~nm}$. Each sample was measured in triplicate.

\subsubsection{Oxygen Radical Absorbing Capacity (ORAC)}

The ORAC assay was conducted according to Chambi et al. [16] and the results were expressed as $\mu \mathrm{moL}$ trolox equivalent (TE)/g DM sample. Briefly, $30 \mu \mathrm{l}$ leaf extract, 
blank or standard mixed with $225 \mu$ of $81.6 \mathrm{nM}$ fluorescein (FL) in a 96-well plate. Incubate covered plate for 20 minutes in plate reader preheated to $37^{\circ} \mathrm{C}$, and then added $25 \mu \mathrm{L}$ of $0.36 \mathrm{M}$ APPH solution to each well to start reaction. Take fluorescence readings of uncovered plate every minute using excitation wavelength of $493 \mathrm{~nm}$ and emission wavelength of $535 \mathrm{~nm}$ at $37^{\circ} \mathrm{C}$ by a Synergy 2Multi-Mode Microplate Reader (BioTek, Winooski, VT, USA). The assay was done in triplicate.

\subsection{Antibacterial Activity}

Two Gram-positive bacteria (Staphylococcus aureus and Listeria monocytogenes), two Gram-negative bacteria (Salmonella typhimurium and Escherichia coli) and fungi(MonilinaVaccinii-corybosi)were used to test the antimicrobial activity of different solvent extracts of blueberry leaves. All microorganisms were obtained from Food Safety and Microbiology Laboratory, Shanghai Jiao Tong University, China.

Preliminary antibacterial screening and minimum inhibitory concentration (MIC) assays were done following the previous methods with some modifications [17]. Briefly, sterilized blank disks of $6 \mathrm{~mm}$ diameter were punched from qualitative filter paper sheets and dipped into the prepared crude leaf extract. The disks were allowed to dry in the laminar flow. The negative control and positive control disks were prepared by applying same volume of pure water and $0.84 \%(\mathrm{w} / \mathrm{v})$ Ciprofloxacin in $0.1 \mathrm{~mol} / \mathrm{L} \mathrm{HCl}$, respectively. The optimized bacterial cultures, equivalent to 0.5 McFarland turbidity standard, were aseptically spread on the entire area of Petri plates containing plate count agar, and were then allowed to dry. The disks containing the blueberry leaf crude extracts, negative control (water), and positive control $(0.84 \%(\mathrm{w} / \mathrm{v})$ Ciprofloxain in $0.1 \mathrm{~mol} / \mathrm{L} \mathrm{HCl}$ ) were aseptically placed on the seeded plates and then placed in an incubator with constant temperature(Thermo Fisher Scientific Co., Model Hera therm, USA)for 15 min to dry. The inhibition zones were measured after $24 \mathrm{~h}$ of incubation at $37^{\circ} \mathrm{C}$, except for fungi which was incubated for $48 \mathrm{~h}$ in an inverted position. All tests were run in triplicate.

To determine MIC of each extract, a broth microdilution method was performed. Ninety-six well culture plates were prepared, and serial two-fold dilutions of the extracts were dispensed into the plate wells. The volume of dispensed extract was $0.1 \mathrm{~mL}$ per well in a concentration range of $5 \%-0.3125 \%$. The same volume $(0.1 \mathrm{~mL})$ of overnight bacterial culture at a density of $10^{6}$ $\mathrm{CFU} / \mathrm{mL}$ was added to the wells, and the bacterial activity in the test wells was detected by adding $20 \mu \mathrm{L} 1 \%(\mathrm{w} / \mathrm{v})$ triphenyltetrazoliumchloride (TTC) aqueous solution. The plates were incubated in an incubator (Thermo Fisher Scientific Co., Model Hera Therm, USA) at $37^{\circ} \mathrm{C}$ for $24 \mathrm{~h}$.
The lowest concentration of the plant extract required to inhibit visible growth of the tested microorganism was designated as the MIC.

\subsection{Statistical Analysis}

Two-way analysis of variance (ANOVA) of the data was carried out using Statistical Packages for the Social Sciences (SPSS 19.0) software. Mean differences were established by the Duncan's multiple range tests. The significant differences $(p<0.05)$ between the means were performed to determine the effect of solvent polarity on the phenolics contents and antioxidant activity of blueberry leaf extracts.

\section{Results and Discussion}

\subsection{Total Phenolic Content}

Polyphenols are a broad family of naturally-occurring physiologically active compounds in nutrition and medicine because of their potent antioxidant capacity and possible protective effects on human health [5]. Table 1 shows the total phenolic content estimated to be in the range from 95.17 to $275.68 \mathrm{mg}$ GAE/g DMl depending on extraction solvents. Skupien et al. [18] reported that the TPC in blueberry (Vacciniumcorymbosum L.) leaf extracts was $111.5 \mathrm{mg} / 100 \mathrm{~g}$ dried leaves. Generally, the TPC of plant extracts increased by increasing polarity of solvent and can also be affected by extraction method such as soxhlet extraction, conventional extraction, etc. [9]. The solvents used in this study can be arranged as follows (starting from high polar solvents): Moisture $>$ Methanol> Ethanol $>$ Acetone. Thus, it is noted that both $70 \%$ acetone and pure methanol extracts demonstrated significantly higher TPC than ethanol extracts $(p<0.05)$. Furthermore, the $95 \%$ ethanol extracts contained the lowest levels of phenolic compounds. This is in accordance with the findings by Naczk et al. [12], who stated that the phenolics contents extracted from blueberry leaves with $70 \%(\mathrm{v} / \mathrm{v})$ acetone were higher than those of $95 \%(\mathrm{v} / \mathrm{v})$ ethanol extracts. Zhou and Yu [19] also reported that the highest level of total phenolics was in 50\% acetone extracts from wheat, whereas ethanol is the least effective solvent for wheat bran samples. It was deduced that acetone solution was effective for extraction of antioxidants because of its good solubility for phenolic components [3]. Moreover, Tomsone et al. [20] reported that the TPC of horseradish was higher in $95 \%$ ethanol extracts than $100 \%$ acetone ones. These divergent results may be caused by different solvents, solvent concentrations, extraction methods and plant varieties.

Table 1. Total phenolic content, tannins, 1,1-diphenyl-2-picrylhydrazyl (DPPH), reducing power and oxygen radical absorbance capacity (ORAC) of blueberry leaf extracts

\begin{tabular}{|c|c|c|c|c|c|}
\hline Solvents & $\begin{array}{c}\text { Total phenols } \\
\text { (mg GAE/g DM) }\end{array}$ & $\begin{array}{c}\text { Tannins } \\
\text { (mg /g DM) }\end{array}$ & $\begin{array}{c}\text { DPPH } \\
\text { (mg AAE/g DM) }\end{array}$ & $\begin{array}{l}\text { Reducing power } \\
\text { (A700 nm) }\end{array}$ & $\begin{array}{c}\text { ORAC } \\
(\mu \mathrm{moL} \text { TE/g DM })\end{array}$ \\
\hline Ethanol (50\%) & $128.67 \pm 0.28^{\mathrm{b}}$ & $2.17 \pm 0.02^{c}$ & $178.95 \pm 1.99^{\mathrm{b}}$ & $0.56 \pm 0.00^{\mathrm{d}}$ & $2040.89 \pm 48.24^{b}$ \\
\hline Ethanol (95\%) & $95.17 \pm 1.20^{\mathrm{a}}$ & $1.94 \pm 0.07^{\mathrm{b}}$ & $129.74 \pm 1.10^{\mathrm{a}}$ & $0.44 \pm 0.00^{\mathrm{c}}$ & $1763.09 \pm 45.60^{\mathrm{a}}$ \\
\hline Acetone (70\%) & $271.97 \pm 3.00^{c}$ & $1.66 \pm 0.06^{\mathrm{a}}$ & $343.59 \pm 3.14^{c}$ & $0.37 \pm 0.01^{\mathrm{b}}$ & $1703.80 \pm 18.48^{\mathrm{a}}$ \\
\hline Methanol (100\%) & $275.68 \pm 0.86^{\mathrm{c}}$ & $2.19 \pm 0.06^{\mathrm{c}}$ & $360.49 \pm 2.59^{d}$ & $0.36 \pm 0.00^{\mathrm{a}}$ & $1751.08 \pm 21.13^{\mathrm{a}}$ \\
\hline
\end{tabular}

DPPH: 1,1-diphenyl-2-picrylhydrazyl; ORAC: oxygen radical absorbance capacity; RP: reducing power.

Each value is expressed as average \pm standard error $(\mathrm{SE})(\mathrm{n}=3)$.

Means in same column with same capital letters are not significantly different $(\mathrm{P}<0.05)$. 


\subsection{Total Tannins Content}

Tannins, another major group of polyphenols in our diets, are the important plant secondary metabolites [21].The amounts of total tannins in the blueberry leaf extracts are shown in Table 1 . Thehighest value of tannins was obtained in both 50\% ethanol and 100\% methanol extracts. It was slightly reduced in $95 \%$ ethanol extracts while the smallest value was found in $70 \%$ acetone extracts. Iniyavan et al. [21] stated that the total phenolic and tannin contents were higher (7-fold and 46-fold, respectively) in pure acetone extracts of $P$. nilgiriensisleaves than in pure methanolextracts.

\subsection{Identification of Phenolic Compounds by HPLC}

Polyphenol qualitative determination of the blueberry leaves was performed by HPLC analysis. As it is shown in Table 2, nine phenolic components were identified including gallic acid, protocatechui acid, caffeic acid, vanillic acid, syringic acid, p-coumaric acid, ferulic acid, quercetin and kaempferol. The results also demonstrated that the blueberry leaves were rich in phenolic compounds such as flavonoids and phenolic acids, which are widely known as antioxidants and antimicrobial agents [1,5]. Those phenolic compounds varied with different extract solvents. The major compounds were caffeic (68.06\%), syringic (11.76\%) and ferulic acid (9.49\%) in 50\% ethanol extracts, as well as protocatechuic (39.48\%), caffeic (32.23\%) and vaillic (15.70\%) in 95\% ethanol extracts.
Caffeic (45.17\% and 59.75\%), syringic (16.06\% and $24.10 \%)$ and p-coumaric acids (24.10\% and8.77\%) were main components in $70 \%$ acetone and methanol extracts, respectively. Furthermore, ferulic acids were not detected in 95\% ethanol and methanol extracts, and quercetin was not yet found in $95 \%$ ethanol and $70 \%$ acetone extracts. Only the $50 \%$ ethanol extracts contained $0.102 \mathrm{mg} / \mathrm{g}$ kaempferol. The amount of each component is not the same in four different solvent extracts. For instance, the highest level of gallic acid was found in 70\% acetone extracts, while there was no significant difference in 95\% ethanol and methanol extracts $(p>0.05)$. Protocatechuic content in 95\% ethanol extracts was higher than in other extracts, and there were no obvious variations among the other three extracts. The concentration of p-coumaric acid was the greatest in $70 \%$ acetone extracts followed by methanol and 50\% ethanol extracts, while the smallest amount was in $95 \%$ ethanol extracts. Similar results were reported by Skupień et al. [18], who observed that the main compoundsin blueberry (Vacciniumcorymbosum L.) leaf extracts were caffeic acid (67.4 mg/100g), querectin (21.6 mg/100g), ellagic acid (15 mg/100g), kaempferol $(5.9 \mathrm{mg} / 100 \mathrm{~g})$ and galic acid $(1.6 \mathrm{mg} / 100 \mathrm{~g})$. Harris et al. [22] reported the levels of chlorogenic acid, epicatechin, catechin, caffeic acid and quercetin in the $95 \%$ ethanol extracts from low bush blueberry (VacciniumangustifoliumAit.) leaves are $31.19,7.25,6.16,0.36$ and $1.24 \mathrm{mg} / \mathrm{g}$ dry matter, respectively. These different results may be dependent on species, extraction method, maturityand growth location.

Table 2. Main phenolic components identified in blueberry leaf extracts

\begin{tabular}{|c|c|c|c|c|}
\hline $\begin{array}{l}\text { Compounds } \\
\text { (mg/g DM) }\end{array}$ & $\begin{array}{c}\text { Ethanol } \\
(50 \%)\end{array}$ & $\begin{array}{c}\text { Ethanol } \\
(95 \%)\end{array}$ & $\begin{array}{c}\text { Acetone } \\
(70 \%)\end{array}$ & $\begin{array}{c}\text { Methanol } \\
(100 \%)\end{array}$ \\
\hline Gallic acid & $0.105 \pm 0.000^{\mathrm{Ca}}$ & $0.408 \pm 0.000^{\mathrm{Ab}}$ & $0.478 \pm 0.002^{\mathrm{ABC}}$ & $0.422 \pm 0.025^{\mathrm{Ab}}$ \\
\hline Protocatechuic acid & $0.293 \pm 0.000^{\mathrm{Da}}$ & $9.510 \pm 0.835^{\mathrm{Eb}}$ & $0.342 \pm 0.000^{\mathrm{ABa}}$ & $0.289 \pm 0.000^{\text {Аа }}$ \\
\hline Caffeic acid & $11.879 \pm 0.001^{\mathrm{Ib}}$ & $7.765 \pm 0.000^{\mathrm{Da}}$ & $6.858 \pm 0.424^{\mathrm{Ea}}$ & $7.819 \pm 2.440^{\mathrm{Ca}}$ \\
\hline Vanillic acid & $0.085 \pm 0.000^{\mathrm{Aa}}$ & $3.631 \pm 0.019^{\mathrm{Cc}}$ & $0.442 \pm 0.000^{\mathrm{ABb}}$ & $0.069 \pm 0.000^{\mathrm{Aa}}$ \\
\hline Syringic acid & $2.052 \pm 0.000^{\mathrm{Ha}}$ & $2.165 \pm 0.000^{\mathrm{Ba}}$ & $2.438 \pm 0.599^{\mathrm{Cab}}$ & $3.154 \pm 0.134^{\mathrm{Bb}}$ \\
\hline P-coumaric acid & $0.865 \pm 0.000^{\mathrm{Fb}}$ & $0.612 \pm 0.169^{\mathrm{Aa}}$ & $3.658 \pm 0.000^{\mathrm{Dd}}$ & $1.148 \pm 0.054^{\mathrm{ABc}}$ \\
\hline Ferulic acid & $1.657 \pm 0.000^{\mathrm{Gb}}$ & ND & $0.965 \pm 0.142^{\mathrm{Ba}}$ & ND \\
\hline Quercetin & $0.415 \pm 0.001^{\mathrm{Eb}}$ & ND & ND & $0.185 \pm 0.000^{\mathrm{Aa}}$ \\
\hline Kaempferol & $0.102 \pm 0.000^{\mathrm{B}}$ & ND & ND & ND \\
\hline
\end{tabular}

ND means not detected.

Each value is expressed as an average \pm standard error (SE) ( $n=3)$.

Means in same column with same capital letters are not significantly different $(\mathrm{P}<0.05)$.

Means in same row with same lowercase letters are not significantly different $(\mathrm{P}<0.05)$.

\subsection{Antioxidant Activity and Correlation Analysis}

The antioxidant capacities may be due to a number of different mechanisms, such as free radical scavenging, reducing capacity and oxygen radical absorbing capacity [23]. Therefore, several analytical methods and different substrates are used for assessing the effectiveness of antioxidants. As shown in Table 1, the extraction solvents significantly (p <0.05) affected DPPH, ORAC and reducing power. The DPPH radical is a stable lipophilic free radical and always employed for evaluating the free radical scavenging potential of plant extract antioxidants. The results of DPPH tests were expressed as mg of ascorbic acid per $1 \mathrm{~g}$ of dry plant material: the higher the values, the higher the antioxidant activity. As seen in Table 1, the solvent was a significant factor on DPPH values. The greatest DPPH scavenging activity was shown in the methanol extracts (360.49mg AAE/g DM) followed by the $70 \%$ acetone extracts (343.59mg AAE/g DM) and the $50 \%$ ethanol extracts (178.95mg AAE/g DM), and the lowest in the 95\% ethanol extract (129.74 mg AAE/g DM).However, Tomsone et al. [20] found that DPPH scavenging activity of horseradish roots No. 105 was twice in the $95 \%$ ethanolic extracts than in the $100 \%$ acetone extracts. There was no significant difference for DPPH scavenging activity of flax seeds extracts between $100 \%$ methanol and $80 \%$ ethanol extracts [24]. The discrepancy in the results of DPPH scavenging ability of the acetone, methanolic and ethanolic extracts might be caused by different mechanisms of reaction, phytochemical constituents being extracted, species, and solvent concentrations.

Reducing power (RP), an important indicator of its antioxidant activity, was evaluated by the $\mathrm{Fe}^{3+}$ to $\mathrm{Fe}^{2+}$ transformations in the presence of plant extracts. The RP 
was expressed as absorbance values at $700 \mathrm{~nm}$ : greater the absorbance and higher reducing activity. The solvents used resulted in different effects on the reductive ability of leaf extracts. The reducing capacities from blueberry leaf extracts in decreasing order are as follows: 50\% ethanol, 95\% ethanol, 70\% acetone and methanol. Anwar et al. [24] stated that the highest reducing power of flaxseeds extracts was in $100 \%$ methanolic extract followed by $80 \%$ and $100 \%$ ethanolic extracts at the concentration from 300$500 \mu \mathrm{g} / \mathrm{mL}$, while no significant difference was found with the concentration less than $200 \mu \mathrm{g} / \mathrm{mL}$ between $100 \%$ methanolic extract and $80 \%$ ethanolic extract. Kaneria and Chana [7] reported that the reducing power of Syzygiumcumini leaves extracted with acetone increased from 0.33 to 1.93with an rise of extract concentration from 20 to 180 $(\mu \mathrm{g} / \mathrm{mL})$. Variations in concentrations and species may explain the above phenomena.

The oxygen radical absorbance capacity (ORAC) assay was also used to demonstrate variations in antioxidant properties of fruit and vegetable extracts. ORAC values ranged from 1751.08 to $2040.89 \mu \mathrm{moLTE} / \mathrm{g}$ DM (Table 1) in present study. Similar results were reported by Buřičován et al. [25], who found that the ORAC values of water raspberry, strawberry, blackberry and green tea leaves extracts were 888, 1062, 1304.3, 1628.6 $\mu \mathrm{moL} \mathrm{TE/g}$ DM. This study showed that the highest oxygen radical absorbing capacity was obtained from the 50\% ethanol extracts, followed by $70 \%$ acetone extracts, $95 \%$ ethanol extracts and pure methanol extracts. Moreover, there was no significant difference among 95\% ethanol, $70 \%$ acetone and methanol extracts $(p<0.05)$.

Calculated coefficients of correlations between antioxidant activities (DPPH, RP and ORAC) and contents of active compounds (total phenolic and tannin) in blueberry leaf extracts were shown in Tables 3.Generally, the DPPH tests were highly positive with active compounds, while the results of RP and ORAC were found negatively correlated with active compounds. For scavenging effects on radicals, results indicated that in $50 \%$ ethanol and $70 \%$ acetone samples highest correlation was observed between TPC and DPPH (>97.8\%), whereas in $50 \%$ and $95 \%$ ethanol extracts, good correlation was observed between Tannin and DPPH (86.2\% and 97.7\%). According to Table 3, a highly negative relationship existed between TPC and RP in methanol extracts (92.9\%), and similar negative correlation was found in Tannin and $\mathrm{RP}$ in $70 \%$ acetone and methanol extracts with correlations being $96.7 \%$ and $93.1 \%$, respectively. Moreover, TPC in 95\% ethanol extracts (99.3\%), and Tanninin 50\% ethanol (98.1\%) and methanol extracts (96.8\%) were also well negative correlated with ORAC data.

Table 3. Correlation between total phenolic content, tannins and antioxidant activity of blueberry leaf extracts

\begin{tabular}{|c|c|c|c|c|}
\hline Correlation $\mathrm{R}^{2}(\%)$ & Ethanol (50\%) & Ethanol (95\%) & Acetone $(70 \%)$ & Methanol (100\%) \\
\hline TPC vs. DPPH & 97.8 & $21.8^{\mathrm{A}}$ & 98.8 & 32.7 \\
\hline TPC vs. RP & $18.9^{\mathrm{A}}$ & $35.9^{\mathrm{A}}$ & 75.6 & $92.9^{\mathrm{A}}$ \\
\hline TPC vs. ORAC & $59.0^{\mathrm{A}}$ & $99.3^{\mathrm{A}}$ & 46.2 & $24.6^{\mathrm{A}}$ \\
\hline Tannin vs. DPPH & 86.2 & 97.7 & 8.6 & 20.9 \\
\hline Tannin vs. RP & $80.3^{\mathrm{A}}$ & $45.4^{\mathrm{A}}$ & $96.7^{\mathrm{A}}$ & $93.1^{\mathrm{A}}$ \\
\hline Tannin vs. ORAC & $98.1^{\mathrm{A}}$ & $35.4^{\mathrm{A}}$ & 56.8 & $96.8^{\mathrm{A}}$ \\
\hline
\end{tabular}

TPC: total phenolic contents; DPPH: 1,1-diphenyl-2-picrylhydrazyl; ORAC: oxygen radical absorbance capacity; RP: reducing powe.

A Shows negative correlation.

\subsection{Antimicrobial Activity}

The crude extracts were screened for their antimicrobial activities against Gram-positive bacteria ( $S$. aureus, and L.monocytogenes), Gram-negative bacteria (E. coli, and $S$. Typhimurium) and fungi. Table 4 displayed that 50\% ethanol extracts of blueberry leaves were active against four bacteria and fungi, and the highest inhibitory effects were found on S. aureus. Both 95\% ethanolic and 100\% methanolic extracts had higher antimicrobial activities for fungi than for other four bacteria. The zones of inhibition (mm)of the $70 \%$ acetone extracts displayed no significant differences among all tested microorganisms. Only the 95\% ethanol extracts showed no effects against L.monocytogenes. These variations may be associated with different structures of cell surface between Gramnegative and Gram-positive bacteria [5]. The higher antifungal activity exhibited the methanol portion and $95 \%$ ethanol may be due to the presence of substantial amounts of polar constitutes from the leaves. This is in agree with previous research report on the antifungal properties of the leaf extract of Aloe vera extracted with pure methanol and ethanol [26].

Table 4. Antimicrobial activities of blueberry leaf extracts

\begin{tabular}{|c|c|c|c|c|c|}
\hline \multirow[b]{2}{*}{ Microorganism } & \multirow[b]{2}{*}{ Indices } & \multicolumn{4}{|c|}{ Antimicrobial activity } \\
\hline & & $\begin{array}{c}\text { Ethanol } \\
(50 \%)\end{array}$ & $\begin{array}{c}\text { Ethanol } \\
(90 \%)\end{array}$ & $\begin{array}{c}\text { Acetone } \\
(70 \%)\end{array}$ & Methanol (100\%) \\
\hline \multirow[t]{2}{*}{ E. coli } & Inhibition zone & + & + & + & + \\
\hline & MIC (mg/mL) & 25 & 25 & 25 & 25 \\
\hline \multirow[t]{2}{*}{ S. Typhimurium } & Inhibition zone & + & + & + & + \\
\hline & MIC (mg/mL) & 25 & 25 & 50 & 50 \\
\hline \multirow[t]{2}{*}{ L. monocytogenes } & Inhibition zone & + & - & + & + \\
\hline & MIC (mg/mL) & 25 & 25 & 25 & 25 \\
\hline \multirow[t]{2}{*}{ S. aureus } & Inhibition zone & ++ & + & + & + \\
\hline & MIC (mg/mL) & 12.5 & 25 & 25 & 37.5 \\
\hline \multirow[t]{2}{*}{ Fungi } & Inhibition zone & + & ++ & + & ++ \\
\hline & MIC (mg/mL) & 25 & 12.5 & 25 & 12.5 \\
\hline
\end{tabular}

Inhibition zone <6 mm: no antimicrobial activity (-); inhibition zone 6-7.5 mm: antimicrobial activity (+); inhibition zone >7.5 mm: high antimicrobial activity (++).

MIC: minimal inhibitory concentration $(\mathrm{mg} / \mathrm{mL})$. 
The MIC values for all the extracts are presented in Table 4. The MIC values for four different solvent extracts were equal for both E. coli. and L.monocytogenes. The MIC values for specie like $S$. Typhimurium were higher in $70 \%$ acetone extracts than in pure methanol ones. For $S$. aureus, the smallest MIC value was found in 50\% ethanol extracts, and the greatest one was in $100 \%$ methanol extracts, while the MIC values did not differ between 95\% ethanol and $70 \%$ acetone extracts. The MIC values for fungi were higher in both $50 \%$ ethanol and $70 \%$ acetone than those in other solvents.

The antimicrobial activities of plant extracts may reside in a variety of different components, such as phenolic acids, flavonoids, tannins, alkaloid, terpenoid, solfoxide and lactone [1,5]. It has been reported that gallic acid, vanillin, eugenol, eugeniin, acetyl eugenol, quercetic acid in the clove bud extracts were effective against L.monocytogenes, S.aureus and Salmonella [4]. The presence of quercetagetin, patuletin, kaempferol and quercetin glycosides from Anthemiscotula flowers had good antimicrobial activity against both Gram-negative and Gram-positive microorganisms [27]. Caffeic acids in tarragon and thyme were effective against viruses, bacteria, and fungi [5,28]. Min et al. [29] found that S. aureus and E. coli exhibited dose dependent and susceptibility $(P<$ 0.01 ) when exposed to $4 \mathrm{mg} / \mathrm{ml}$ of the tannin monomers from eight different woody plant species extracts. Many researches showed phenolic compounds in the plant had contributed to the antimicrobial properties, and the antimicrobial capacity was dependent on the action mode of polyphenols, source and concentration of phenolic compounds, extraction methods, varieties and microorganism species $[1,5,6,29]$. Moreover, there are the synergistic effect of all kinds of phenolic compounds on bacterial stains and fungi species [30]. These may be used to explain the different antimicrobial capacities of the extracts using different extracted solvents.

\section{Conclusion}

The current results showed that themethanolic extracts from blueberry leaves had the highest levels of total phenolic contents, tannins and DPPH capacity as well as the lowest RF, while the largest RF and ORAC values were found in $50 \%$ ethanol extracts. Among 9 phenolic compounds identified by HPLC, ferulic acids, quercetin and kaempferol were not detected in 95\% ethanol extracts. Quercetin and kaempferol were not found in acetone extracts. The methanol extracts had no ferulic acids and kaempferol. Good correlations were found between antioxidant activities (DPPH, RP and ORAC) and active compounds (tannin and TPC) contents. All extracts (except for 95\% ethanol for L.monocytogenes) were active against Gram-positive bacteria, Gram-negative bacteria and fungi in this study. The $50 \%$ ethanol extracts showed the highest inhibitory effects against $S$. aureus and the lowest MIC against all the bacteria. Both 95\% ethanol and methanol extracts demonstrated the greatest inhibition zone and the smallest MIC for fungi. The current study indicated blueberry leaves have favorable antioxidant and antimicrobial potential and could be a good source of natural antioxidants and antimicrobials. More research in the future is required to investigate the effects of plant ripeness, extracted parameters (such as solvent concentration, temperature, time) on the functionalities of the extracts and the stability of extract methods.

\section{Acknowledgements}

This research was funded by the National Natural Science Foundation of China (31301586), the Key Project of Education Department Henan Province (13A210729), the Youth science and technology innovation talents support program of North China University of Water Resources and Electric Power (70442).

\section{References}

[1] Gurjar M S, Ali S, Akhtar M, et al., Efficacy of plant extracts in plant disease management. Agricultural Sciences, 2012; 3: 425433.

[2] Merkl R, HrádkoVá I, Filip V, et al., Antimicrobial and antioxidant properties of phenolic acids alkyl esters. Czech J Food Science, 2010; 28: 275-279.

[3] Roby M H H, Sarhan M A, Selim K A H, et al., Evaluation of antioxidant activity, total phenols and phenolic compounds in thyme (Thymus vulgaris L.), sage (Salvia officinalis L.), and marjoram (Origanum majorana L.) extracts. Industrial Crops and Products, 2013; 43: 827-831.

[4] Gutiérrez-Larraínzar M, Rúa J, Caro I, et al., Evaluation of antimicrobial and antioxidant activities of natural phenolic compounds against foodborne pathogens and spoilage bacteria. Food Control, 2012; 26: 555-563.

[5] Cowan M M. Plant products as antimicrobial agents. Clinical Microbiology Reviews, 1999; 12: 564-582.

[6] Fernández-AgullóA, Pereira E, Freire M S, et al., Influence of solvent on the antioxidant and antimicrobial properties of walnut (Juglans regia L.) green husk extracts. Industrial Crops and Products, 2013; 42: 126-132.

[7] Kaneria M, Chanda S. Evaluation of antioxidant and antimicrobial capacity of Syzygium cumini L. leaves extracted sequentially in different solvents. Journal of Food Biochemistry, 2012; 37: 168176.

[8] Kchaou W, Abbès F, Blecker C, et al., Effects of extraction solvents on phenolic contents and antioxidant activities of Tunisian date varieties (Phoenix dactylifera L.). Industrial Crops and Products, 2013; 45: 262-269.

[9] Michiels J A, Kevers C, Pincemail J, et al., Extraction conditions can greatly influence antioxidant capacity assays in plant food matrices. Food Chemistry, 2012; 130: 986-993.

[10] Li C, Feng J, Huang W Y, An X T. Composition of polyphenols and antioxidant activity of rabbiteye blueberry (vaccinium ashei) in Nanjing. Journal of Agricultural and Food Chemistry, 2013; 61: 523-531.

[11] Piljac-Žegarac J, Belščak A, Piljac A. Antioxidant capacity and polyphenolic content of blueberry (Vaccinium corymbosum L.) leaf infusions. Journal of Medicinal Food, 2009; 12: 608-614.

[12] Naczk M, Grant S, Zadernowski R, et al., Protein precipitating capacity of phenolics of wild blueberry leaves and fruits. Food Chemistry, 2006; 96: 640-647.

[13] Moulehi I, Bourgou S, Ourghemmi I, et al., Variety and ripening impact on phenolic composition and antioxidant activity of mandarin (Citrus reticulate Blanco) and bitter orange (Citrus aurantium L.) seeds extracts. Industrial Crops and Products, 2012; 39: 74-80.

[14] CHNSA. Determination of tannin content in fruit, vegetable and derived product-spectrophotometry method. China National Standard (Agriculture) NY/T 1600-2008; 2008.

[15] Brand-Williams W, Cuvelier M, Berset C. Use of a free radical method to evaluate antioxidant activity. LWT-Food Science and Technology, 1995; 28: 25-30.

[16] Chambi F, Chirinos R, Pedreschi R, et al., Antioxidant potential of hydrolyzed polyphenolic extracts from tara (Caesalpinia spinosa) pods. Industrial Crops and Products, 2013; 47: 168-175. 
[17] Khurram M, Hameed A, Khan M A, et al., Antibacterial potentials of quercus baloot griff. Journal of Medicinal Plants Research, 2012; 6: 1244-1249.

[18] Skupień K, Oszmiański J, Kostrzewa-Nowak D, et al., In vitro antileukaemic activity of extracts from berry plant leaves against sensitive and multidrug resistant HL60 cells. Cancer letters, 2006; 236: 282-291.

[19] Zhou K, Yu L. Effects of extraction solvent on wheat bran antioxidant activity estimation. LWT-Food Science and Technology, 2004; 37: 717-721.

[20] Tomsone L, Kruma Z, Galoburda R. Comparison of different solvents and extraction methods for isolation of phenolic compounds from Horseradish roots (Armoracia rusticana). World Academy of Science, Engineering and Technology, 2012; 64: 903908.

[21] Iniyavan M, Sangeetha D, Saravanan S, et al., Evaluation of antioxidant and pharmacological properties of Psychotria nilgiriensis Deb \& gang. Food Science and Biotechnology, 2012; 21: 1421-1431.

[22] Harris C S, Burt A J, Saleem A, et al., A single HPLC-PADAPCI/MS method for the quantitative comparison of phenolic compounds found in leaf, stem, root and fruit extracts of Vaccinium angustifolium. Phytochemical Analysis, 2007; 18: 161169.

[23] Chen H Y, Yen G C. Antioxidant activity and free radicalscavenging capacity of extracts from guava (Psidium guajava L.) leaves. Food Chemistry, 2007; 101: 686-694.
[24] Anwar F, Przybylski R. Effect of solvents extraction on total phenolics and antioxidant activity of extracts from flaxseed (Linum usitatissimum L.). ACTA Scientiarum Polonorum Technologia Alimentaria, 2012; 11: 293-301.

[25] Buřičován L, Andjelkovic M, Čermáková A, et al., Antioxidant capacity and antioxidants of strawberry, blackberry, and raspberry leaves. Czech Journal of Food Science, 2011; 29: 181-189.

[26] Khaing $T$ A. Evaluation of the antifungal and antioxidant activities of the leaf extract of aloe Vera (Aloe barbadensis Miller). World Academy of Science, Engineering and Technology, 2011; 75: 610612.

[27] Quarenghi M, Tereschuk M, Baigori M, \& Abdala, et al., Antimicrobial activity of flowers from Anthemis cotula. Fitoterapia, 2000; 71: 710-712.

[28] Masuda T, Yamada K, Akiyama J, et al. Antioxidation mechanism studies of caffeic acid: identification of antioxidation products of methyl caffeate from lipid oxidation. Journal of Agricultural and Food Chemistry, 2008; 56: 5947-5952.

[29] Min B, Pinchak W, Merkel R, Walker S, et al. Comparative antimicrobial activity of tannin extracts from perennial plants on mastitis pathogens. Scientific Research and Essays, 2008; 3: 66-73.

[30] Edris A E, Farrag E S. Antifungal activity of peppermint and sweet basil essential oils and their major aroma constituents on some plant pathogenic fungi from the vapor phase. Food/Nahrung, 2003; 47: 117-121. 